\title{
Cardiovascular Outcomes and the Use of Oral Antidiabetic Drugs: A Review of Current Evidence from Observational Studies
}

Elnaem M.H. ${ }^{a, b}$, Mohd Azam F $F^{a}$, Akkawi ME ${ }^{a, b}$

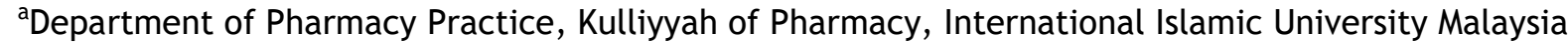

${ }^{b}$ Quality Use of Medicines Research Group, Kulliyyah of Pharmacy, International Islamic University Malaysia

\section{ABSTRACT}

Type 2 diabetes mellitus (T2DM) is a major global disease burden that affects millions of people worldwide. The disease is well known to predispose patients to a wide range of macro- and microvascular complications. Cardiovascular complications are common macrovascular consequences among patients with T2DM. The primary goal of T2DM management is to achieve proper glycaemic control that helps to avoid or delay the incidence of disease complications. T2DM management involves the utilisation of oral antidiabetic medications and injectables, including insulin. Hence, we conducted this work to discuss and summarise the cardiovascular outcomes associated with the oral antidiabetic pharmacotherapy prescribed for patients with T2DM. The agents involved were metformin, sulfonylurea, dipeptidyl peptidase-4 inhibitors, thiazolidinediones, alpha-glucosidase inhibitors, and sodium-glucose cotransporter-2 inhibitors. We decided to focus on the findings reported from observational studies published between 2009 to 2019 to provide an updated and more realistic insight on these cardiovascular outcomes associated with the oral antidiabetic drugs in the usual clinical practice.

KEYWORDS: cardiovascular outcomes, oral antidiabetic drugs, oral hypoglycaemic agents.

\section{INTRODUCTION}

Type 2 diabetes mellitus (T2DM) is a significant global disease burden that affects millions of people worldwide. By the year 2035, it is estimated about 592 million people around the world will have T2DM, which is predominantly associated with insulin secretory defects based on the incidence of insulin resistance related to inflammation, stress, overweight, and obesity. ${ }^{1}$ The disease is well known to predispose patients to a wide range of complications due to alterations of normal physiological functions, leading to macro- and microvascular changes. ${ }^{2}$

Cardiovascular (CV) complications are common macrovascular consequences among patients with T2DM due to their increased susceptibility to metabolic risk factors for atherosclerotic

Corresponding Author:

Asst. Prof. Dr. Mohamed Hassan Elnaem

Department of Pharmacy Practice ,

Kulliyyah of Pharmacy,

International Islamic University Malaysia, 25200

Kuantan, Pahang, Malaysia

Tel No : +0193944726

Email : drmelnaem@iium.edu.my cardiovascular disease. ${ }^{3}$ It has been reported that people with diabetes are at two to four times higher mortality rate due to cardiovascular events compared to healthy individuals. ${ }^{2}$ Moreover, there is an increment for the mortality trend of patients with T2DM attributed to cardiovascular complications, which might inflict a growing burden on the healthcare system and warrant more efforts towards reducing diabetes-related cardiovascular disease. ${ }^{4}$ Although the use of lipid-lowering therapy (LLT) for cardiovascular disease (CVD) prevention among patients with T2DM has been well established, there are reported challenges on the effectiveness of LLT use among patients with T2DM in both, hospital and primary care settings. ${ }^{5,6}$

Moreover, achieving proper glycaemic control, as the primary goal of T2DM management, helps to avoid or delay the incidence of disease complications apart from controlling other cardiometabolic risks. ${ }^{7}$ T2DM management involves the utilisation of oral antidiabetic medications and injectables, including insulin. The role of glycaemic control in managing cardiovascular outcomes is complex because specific oral antidiabetic agents show benefits; meanwhile, 
others carry relatively more risks and hence should be individualised. Therefore, we conducted this work to discuss and summarise the cardiovascular outcomes associated with the oral antidiabetic pharmacotherapy prescribed for patients with T2DM. The involved agents were metformin, sulfonylurea (S.U.), dipeptidyl peptidase-4 inhibitors (DPP4i), thiazolidinediones (TZD), alpha-glucosidase inhibitors, and sodium-glucose cotransporter-2 inhibitors (SGLT2i). We decided to focus on the findings reported from observational studies published between 2009 to 2019 to provide an updated and more realistic insight on these cardiovascular outcomes associated with oral antidiabetic drugs (ADD) in the usual clinical practice.

\section{METHODOLOGY}

A literature search of the published observational studies that reported cardiovascular outcomes associated with the use of ADD was undertaken in December 2019. The searches were limited to the last ten years (2009-2019) to provide a review of the most recently published evidence. Three scientific databases, Google Scholar, Science Direct, and PubMed, were searched using predefined terms. Two reviewers screened all the initially identified studies for its relevancy, English language, and article type (original research involving adult T2DM patients).

Observational studies reported negative or positive effects of oral antidiabetic drugs (ADD) on the CV outcomes among T2DM patients were included. Review articles, meta-analysis studies, case reports, book chapters, and conference proceedings were excluded. A study-specific extraction form was developed and used to retrieve the information from the included studies. The overview chart describing the selection of the articles is illustrated in Figure 1. Moreover, we have formulated the following key research questions to guide our search and decision on the final included studies.

1. What are the commonly reported CV outcomes associated with the use of different oral ADD in observational studies?

2. What are the differences in the reported CV outcomes between various oral ADD either as monotherapy or combination therapy in observational studies?

\section{RESULTS}

Of the initially identified 397 studies, 22 studies were finally included in this review. Concerning the countries in which the research was conducted, a total of nine studies were conducted in Asian countries (Taiwan and South Korea); meanwhile, seven studies were carried out in European countries (Denmark, France, U.K). Also, five studies were undertaken in the U.S. Only one study included data from both the U.S. and European countries (Sweden, Denmark, Norway, and the U.K). ${ }^{8}$ Regarding the sample size included, one-third of the total studies were designed as nationwide and population-based studies. ${ }^{9-16}$ The findings of the included studies show that conventional ADDs, like metformin and S.U., were present in almost more than half of the comparisons with other ADD monotherapies. A relatively fewer number of studies were reported for SGLT2i, where only three studies investigated its associated $\mathrm{CV}$ outcomes. Furthermore, the findings showed that the majority of the studies $(18 / 22)$ included ADD monotherapies, whereas combination therapies were reported in only four out of the 22 included studies. The design, setting, objectives, and main results of the included studies are summarised in table 1 .

\section{DISCUSSION}

Overall, there were differences in the number of observational studies that reported CV outcomes for different ADDs. For example, many studies were available for both metformin and S.U., followed by DDP4i. Meanwhile, relatively few studies were available for newer agents such as SGLT2i. In addition, there were documented differences in the degree of $C V$ benefits and risks associated with ADD monotherapy, particularly in comparative studies. The variations in these reported CV outcomes imply a consequently relative preference of particular agents based on the existing comorbidities and intercurrent illness. ${ }^{30}$

Metformin is a widely prescribed first-line treatment for the majority of T2DM patients. ${ }^{21}$ According to Eurich et al. (2013), the use of metformin for diabetic patients with H.F. either alone or in combination with S.U. lesser morbidity and mortality in comparison to S.U. monotherapy. ${ }^{31}$ Many studies have highlighted the relative $\mathrm{CV}$ benefits of metformin compared to S.U. ${ }^{17,20}$ Moreover, 


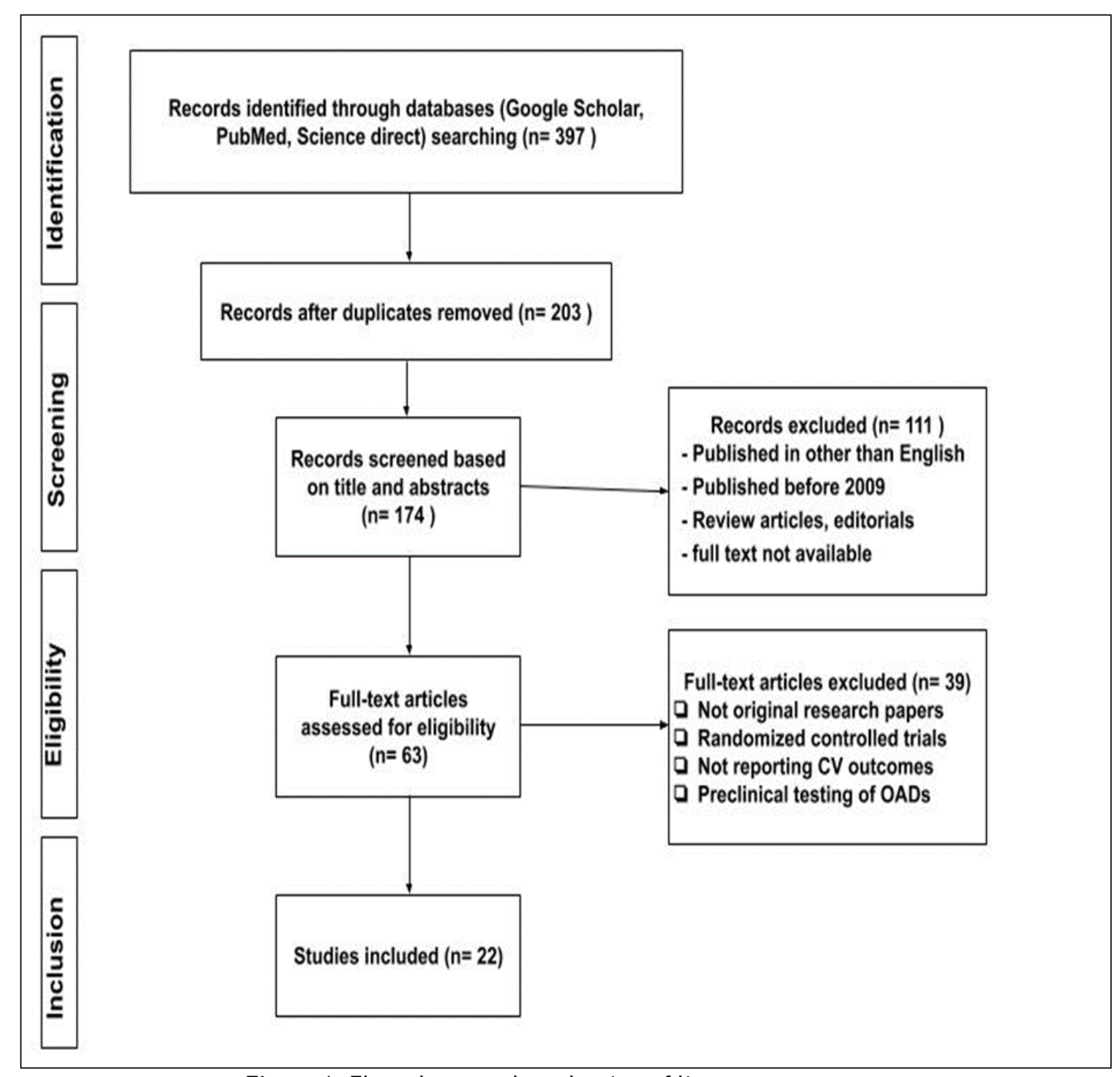

Figure 1: Flow chart on the selection of literature

metformin resulted in better CV outcomes in high-risk patients that is further strengthened with the longterm beneficial impact of metformin related to its antiatherosclerosis properties beyond the glucoselowering effect. ${ }^{32}$ On the other hand, it has been observed that males have a higher risk of metforminassociated myocardial infarction than females implying sex-drug interactions in describing the CV safety of oral ADD. ${ }^{33}$ The trend showed an increased risk of CV death and ischemic stroke for the S.U. therapy compared to metformin monotherapy. ${ }^{34}$ Also, the data that the patients on S.U. more prone to have in-hospital mortality when comparing to the patients who did not receive S.U. treatment. ${ }^{18}$

Furthermore, adding or switching S.U. to metformin associated with decreased risk of $\mathrm{MI}$, severe hypoglycemia, and all-cause mortality compared to metformin monotherapy..$^{34}$ In a French study, it has been highlighted that glibenclamide was associated with a higher risk for in-hospital mortality compared to gliclazide and glimepiride. ${ }^{18}$ Nevertheless, gliclazide treatment was associated with a declined rate of primary endpoint events of major microvascular and macrovascular complications. ${ }^{18}$ Moreover, it is worthy to note that there are few differences between S.U. agents related to their safety profile, such as cardiac adverse events. A Danish nationwide study has highlighted that gliclazide lower CV and mortality risk compared to other S.U. agents, even glimepiride, which was previously hypothesised to reduce MI preconditioning. ${ }^{9}$ The differences in CV safety shown by different S.U.s denote the importance of the careful selection of S.U. agent, particularly in diabetic patients with coronary artery diseases. ${ }^{32}$ As a combination therapy, S.U. added to metformin conferred a higher risk of hospital hospitalisation compared to the DPP4i added to metformin. ${ }^{16}$ Also, as monotherapies, DPP4i a safer ADD to be offered to diabetic patients with H.F. compared to glimepiride. ${ }^{27}$ 
Table 1: Summary of the main characteristics and retrieved information from the included selected studies $(\mathrm{N}=22)$

\begin{tabular}{|c|c|c|c|c|}
\hline $\begin{array}{l}\text { Author \& } \\
\text { Country }\end{array}$ & $\begin{array}{l}\text { Study design \& } \\
\text { population }\end{array}$ & Objectives & Key findings & Conclusion \\
\hline $\begin{array}{l}\text { Tzoulaki et al. } \\
2009^{17} \\
\text { (U.K.) }\end{array}$ & $\begin{array}{l}\text { Retrospective } \\
\text { cohort study } \\
\text { included } 91,521 \\
\text { patients. }\end{array}$ & $\begin{array}{l}\text { To explore the } \\
\text { association between } \\
\text { ADD and H.F. and } \\
\text { all-cause mortality. }\end{array}$ & $\begin{array}{l}\text { - S.U. showed a higher risk of all- } \\
\text { cause mortality. Second- } \\
\text { generation agents showed } \\
\text { significantly } 18 \% \text { to } 30 \% \text { higher } \\
\text { H.F. risk compared to } \\
\text { metformin. }\end{array}$ & $\begin{array}{l}\text { Compared to } \\
\text { metformin, S.U. } \\
\text { had an } \\
\text { increased risk } \\
\text { for H.F., while } \\
\text { pioglitazone had }\end{array}$ \\
\hline & & & - $\quad$ Pioglitazone reduced the risk of & $\begin{array}{l}\text { all-cause } \\
\text { mortality. }\end{array}$ \\
\hline
\end{tabular}

$\begin{array}{ll}\text { Zeller et al. } & \begin{array}{l}\text { Retrospective } \\ \text { Cohort study }\end{array} \\ & \begin{array}{l}\text { included } 1,310 \\ \text { diabetic patients } \\ \text { (France) }\end{array} \\ & \begin{array}{l}\text { who had prior MI } \\ \text { admission. }\end{array}\end{array}$

$\begin{array}{ll}\begin{array}{l}\text { Gallagher et } \\ \text { al. 2011 } 19\end{array} & \begin{array}{l}\text { Cohort study } \\ \text { included 206,940 } \\ \text { T2DM adult }\end{array} \\ \text { (U.K.) } & \text { patients. }\end{array}$

$\begin{array}{ll}\begin{array}{l}\text { Schramm et } \\ \text { al. } 2011^{9}\end{array} & \begin{array}{l}\text { Nationwide } \\ \text { cohort study } \\ \text { involved 107,806 }\end{array} \\ \text { (Denmark) } & \text { T2DM patients. }\end{array}$

Roumie et al. Retrospective $2012^{20}$ cohort study included 253 , (USA) 690 veterans newly initiated on S.U. or metformin monotherapy.

\section{Chen et al. $2014^{10}$}

(Taiwan)
Nationwide cohort study included 644,792 patients without pre-existing CVD who have been initiated on acarbose.
To investigate the link between receiving S.U. before admission and the incidence of $\mathrm{Ml}$ compared to insulin and other ADD.

To assess the CV risk and mortality associated with the use of TZD.

To compare the CVD and mortality risk between insulin secretagogues (I.S.s) and metformin.

To compare the impact of S.U. and metformin on CV outcomes.

To evaluate the possible CV outcomes of acarbose in T2DM patients. metformin.

- $\quad$ S.U. users had a lower mortality risk $(3.9 \%, P=0.014)$, compared to those on insulin $(9.4 \%)$, or other ADD (6.4\%).

- $\quad$ Pancreatic-cell specific agents, e.g., gliclazide and glimepiride, showed significantly lower inhospital mortality $(2.7 \%$, $P=0.019)$ compared to glibenclamide $(7.5 \%)$.

Rosiglitazone showed higher mortality risk (aRR 1.20; $95 \% \mathrm{Cl}$ 1.08-1.34) and HF-related hospitalization (aRR of 1.73; 95\% Cl 1.19-2.51) compared to pioglitazone.

Unlike all I.S.s, gliclazide and repaglinide showed no statistically significant different CVD and mortality risk compared to metformin.

The incidence of adverse CV outcomes was higher in S.U. users compared to metformin users ( aHR: 1.21, Cl, 1.131.30).

- $\quad$ The aHR for CV adverse events was $1.14,0.64$, and 0.41 for the duration of consuming acarbose $<12$ months, 12 to 24 months, and $>24$ months, respectively.

- After the primary CVD, uninterrupted use of acarbose exposed neutral effect within the first 12 months, followed by a positive effect when it was continued for $>12$ months.

To compare the CV outcomes between Mogensen et Retrospective nation-wide study involved patients (Denmark) on S.U. plus insulin $(\mathrm{n}=$ $11,081)$, or metformin plus insulin $(\mathrm{n}=$ $16,910)$.

The S.U. use before the acute $\mathrm{Ml}$ episode showed no additional risk when compared to insulin or other ADDs.

Lower CV risks were reported for pioglitazone in comparison to rosiglitazone.

Gliclazide and repaglinide showed lower CVD and mortality risk compared to other I.S.S. Initial treatment with S.U. was associated with higher risks of CV adverse events compared to metformin.

Acarbose showed a temporary escalation in the CVD incidence in the first 12 months, followed by a substantial decline of CVD in persistent users.

Metformin plus insulin was associated with less adverse CV outcomes compared to S.U. and insulin. 


\begin{tabular}{|c|c|c|c|c|c|}
\hline $\begin{array}{l}\text { Chang et al. } \\
201511 \\
\text { (Taiwan) }\end{array}$ & $\begin{array}{l}\text { Nationwide cohort } \\
\text { study involved } \\
\text { patients received } \\
\text { acarbose ( } \mathrm{n}= \\
17,366 \text { ) or } \\
\text { metformin }(\mathrm{n}=\end{array}$ & $\begin{array}{l}\text { To compare the } \\
\text { CV outcomes } \\
\text { associated with } \\
\text { the initiation of } \\
\text { acarbose and } \\
\text { metformin. }\end{array}$ & & $\begin{array}{l}\text { There was a } 5 \% \text { higher risk of any } \\
\text { CV event and ischemic stroke, } \\
\text { and } 8 \% \text { higher risk of heart } \\
\text { failure among patients received } \\
\text { acarbose compared to }\end{array}$ & $\begin{array}{l}\text { Acarbose } \\
\text { conferred } \\
\text { higher CV risk } \\
\text { compared to } \\
\text { metformin. }\end{array}$ \\
\hline
\end{tabular}
$\begin{array}{ll}\text { Shin \& Kim, } & \begin{array}{l}\text { A retrospective } \\ \text { cold }\end{array}{ }^{22}\end{array}$ involved patients

(South Korea) received sitagliptin $(n=1620)$ or metformin $(n=3240)$

$\begin{array}{ll}\text { Hippisley et } & \text { Open cohort study } \\ \text { al. } 2016^{23} & \text { involved 469,668 } \\ & \text { T2DM patients who } \\ \text { (U.K.) } & \text { were prescribed } \\ & \text { with at least one } \\ & \text { ADD, particularly } \\ & \text { DPP4i and TZD. }\end{array}$

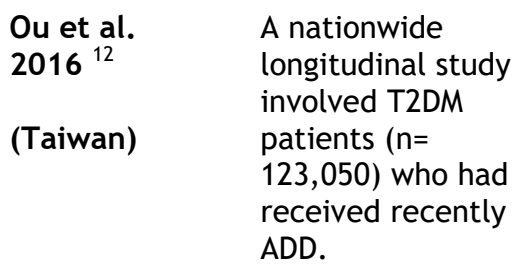

To compare CV safety associated with DPP4i compared to other ADDs.

To evaluate the relationship between the risk of CVD, H.F., and all-cause mortality and the use of ADD. metformin.

There was no significant difference between sitagliptin and metformin in terms of rate of H.F. hospitalization and IHD.

compared to

metformin.

Compared to non-use, TZD was associated with $26 \%, 23 \%$, and $25 \%$ decrease in the risk for H.F., all-cause mortality, and CVD, respectively.

Compared to non-use, DPP4i was linked to a reduction in the H.F. risk and all-cause mortality by $14 \%$; and $18 \%$, respectively.

Meglitinides (aHR 1.3, $95 \% \mathrm{Cl}$ 1.20-1.43) and insulin (aHR 3.73, $95 \% \mathrm{Cl} 3.35-4.14)$ showed a significantly higher risk of adverse CV events compared to DPP4i.

- $\quad$ Metformin users (aHR 0.87, $95 \%$ $\mathrm{Cl}$ 0.79-0.94) have a significantly lower risk of adverse CV events compared to DPP4i users.

$\begin{array}{ll}\text { Heaton et al. } & \begin{array}{l}\text { A retrospective } \\ \text { cohort analysis } \\ \text { ch } \\ \text { included } 13.5 \text { million }\end{array} \\ & \text { T2DM patients on } \\ & \text { oral ADD with a } \\ \text { previous } & \text { hospitalization } \\ & \text { linked to their } \\ \text { diabetes. }\end{array}$

Hsu et al. Nested case-control $2016^{25} \quad$ study included 8936 patients who

(Taiwan) received at least one oral ADD and diagnosed with aortic aneurysm.

Gautam et al., A retrospective $2017^{26} \quad$ cohort study among adult T2DM patients (USA) who received either SGLT2i $(n=4899)$ or DPP4i $(n=9798)$.
To compare between S.U. and other ADDs in terms of the risk for diabetes -related hospitalization readmission.

To explore the association between oral ADD and the risk for development aortic aneurysm.

To evaluate the relative risk of H.F. hospitalization of DPP4i compared to SGLT2i.
The most common readmission cause was cardiovascular disease.

A total of $23.2 \%$ of readmission occurred in patients treated with S.U. monotherapy [HR 1.29, $P=$ 0.04)] compared to $16.1 \%$ with the other oral ADD monotherapies. Metformin, TZD, and S.U. were related to a lesser risk of aortic aneurysm events. Metformin and S.U. effects were dosedependent.

There was no association between alpha-glucosidase inhibitors or DPP-4 inhibitors and aortic aneurysm events.

- $\quad$ The risk of HF hospitalization was lower for the SGLT2i cohort (2\%) compared to the DPP4i cohort (3.1\%) ( aHR 0.68; $P=.001)$.

- $\quad$ The revealed difference was evident only in the subgroups of the elderly and patients with T2DM complications.
Sitagliptin is not linked to the raised risk of CV death and complications in comparison to metformin.

The use of TZDs or DDP4 inhibitors reduces the overall CV risk compared to the non-users of these ADD.

DPP4i use has significantly higher CV safety compared to meglitinides and insulin. However, it is less cardioprotective compared to metformin.

There was 30\% increase in the risk of rehospitalization among patients who received S.U. compared to the other $A D D$.

Metformin, TZD, and S.U. treated patients were found to have a lower risk of aortic aneurysm incidence.

The elderly and patients with diabetic complications were at lower risk of H.F. hospitalization if initiated on SGLT2i compared to DPP4i. 
Con't

\begin{tabular}{|c|c|c|c|c|c|}
\hline $\begin{array}{l}\text { Chin et al. } \\
2017{ }^{27} \\
\text { (South Korea) }\end{array}$ & $\begin{array}{l}\text { Retrospective cohort } \\
\text { Study included T2DM } \\
\text { patients who } \\
\text { received glimepiride } \\
(n=13,447) \text { or DPP4i } \\
(n=6504) .\end{array}$ & $\begin{array}{l}\text { To assess the CV } \\
\text { safety of DDP } 4 i \\
\text { compared to } \\
\text { glimepiride. }\end{array}$ & & $\begin{array}{l}\text { There was no significant } \\
\text { escalation of the total CV events } \\
\text { with the use of DPP4i compared } \\
\text { to glimepiride (aHR, } 0.87 ; 95 \% \\
\mathrm{Cl}, 0.75-1.01) \text {. } \\
\text { DDP4i use showed a decreased } \\
\text { risk of hospitalization for H.F. } \\
\text { compared with the use of } \\
\text { glimepiride (aHR, } 0.58 ; 95 \% \mathrm{Cl} \text {, } \\
0.37-0.89) \text {. }\end{array}$ & $\begin{array}{l}\text { DPP4i did not } \\
\text { elevate CV risk } \\
\text { and could be a } \\
\text { safer option } \\
\text { for H.F. } \\
\text { patients } \\
\text { compared to } \\
\text { glimepiride. }\end{array}$ \\
\hline $\begin{array}{l}\text { Kim et al. } \\
2018^{13} \\
\text { (South Korea) }\end{array}$ & $\begin{array}{l}\text { A nationwide } \\
\text { retrospective study } \\
\text { of } 59,479 \text { patients } \\
\text { on SGLT2i and } \\
\text { matched with those } \\
\text { on DPP4i. }\end{array}$ & $\begin{array}{l}\text { To compare the } \\
\text { H.F. protective } \\
\text { effect of SGLT2i } \\
\text { and DPP } 4 \mathrm{i} \text {. }\end{array}$ & $\bullet$ & $\begin{array}{l}\text { SGLT2i showed a lower risk of } \\
\text { H.F. hospitalization (H.F.: 0.66, } \\
95 \% \text { CI 0.58-0.75) compared to } \\
\text { DPP4i. } \\
\text { The SGLT2i effect was observed } \\
30 \text { days in new users with } \\
\text { underlying CVD and late in } \\
\text { patients without underlying CVD. }\end{array}$ & $\begin{array}{l}\text { SGLT2i has a } \\
\text { better } \\
\text { cardioprotectiv } \\
\text { e effect } \\
\text { compared with } \\
\text { DPP4i, } \\
\text { particularly in } \\
\text { patients with } \\
\text { underlying } \\
\text { CVD. }\end{array}$ \\
\hline $\begin{array}{l}\text { Raghavan et } \\
\text { al. } 2018^{28} \\
\text { (USA) }\end{array}$ & $\begin{array}{l}\text { Cohort study } \\
\text { involved } 5352 \\
\text { veterans patients } \\
\text { with well-controlled } \\
\text { T2DM and CAD. }\end{array}$ & $\begin{array}{l}\text { To compare the } \\
\text { link between } \\
\text { S.U. vs. non-SU } \\
\text { and mortality } \\
\text { risk. }\end{array}$ & & $\begin{array}{l}\text { S.U. users have experienced } \\
\text { unadjusted higher mortality } \\
\text { compared to non-SU ( } 11.9 \% \text { vs. } \\
5.2 \%) \text {. } \\
\text { In a fully adjusted model, there } \\
\text { was no significant difference } \\
\text { between the two groups. }\end{array}$ & $\begin{array}{l}\text { S.U. confer } \\
\text { higher CV risk } \\
\text { compared to } \\
\text { non-SU, e.g., } \\
\text { metformin } \\
\text { among patients } \\
\text { with well- } \\
\text { controlled } \\
\text { T2DM and CAD }\end{array}$ \\
\hline $\begin{array}{l}\text { Chan et al. } \\
2018^{14} \\
\text { (Taiwan) }\end{array}$ & $\begin{array}{l}\text { Retrospective } \\
\text { nationwide cohort } \\
\text { study involved } \\
26,742 \text { patients who } \\
\text { received second-line } \\
\text { ADD. }\end{array}$ & $\begin{array}{l}\text { To assess the CV } \\
\text { risk of adding } \\
\text { second-line ADD } \\
\text { to metformin. }\end{array}$ & • & $\begin{array}{l}\text { TZD (aHR: } 0.66, p=0.004 \text { ) and } \\
\text { alpha-glucosidase inhibitors } \\
\text { (aHR: } 0.74, p=0.01 \text { ) have } \\
\text { significantly lower risk of } \\
\text { adverse CV outcomes compared } \\
\text { to SU. }\end{array}$ & $\begin{array}{l}\text { The add-on } \\
\text { therapy using } \\
\text { alpha- } \\
\text { glucosidase } \\
\text { inhibitors or } \\
\text { TZD was linked } \\
\text { to a lower CV } \\
\text { risk compared } \\
\text { to S.U. }\end{array}$ \\
\hline $\begin{array}{l}\text { Antonios } \\
\text { Douros et al. } \\
2018^{15} \\
\text { (U.K.) }\end{array}$ & $\begin{array}{l}\text { A population-based } \\
\text { cohort study } \\
\text { included } 77,138 \\
\text { patients on } \\
\text { metformin, from } \\
\text { them } 25,699 \\
\text { experienced } \\
\text { addition or switching } \\
\text { to S.U. }\end{array}$ & $\begin{array}{l}\text { To investigate } \\
\text { the impact of } \\
\text { adding or } \\
\text { switching to S.U. } \\
\text { compared to } \\
\text { metformin } \\
\text { monotherapy on } \\
\text { the CV safety. }\end{array}$ & - & $\begin{array}{l}\text { Compared to metformin, S.U. } \\
\text { was associated with } 26 \%, 28 \% \\
\text { increase in the risk of } \mathrm{MI} \text {, and } \\
\text { all-cause mortality, } \\
\text { respectively. } \\
\text { Switching to S.U. was found to } \\
\text { confer higher MI risk compared } \\
\text { to adding it with metformin } \\
\text { therapy }\end{array}$ & $\begin{array}{l}\text { S.U. use } \\
\text { conferred } \\
\text { higher CV risk } \\
\text { compared to } \\
\text { metformin } \\
\text { monotherapy. } \\
\text { Adding S.U. to } \\
\text { metformin had } \\
\text { a lower risk } \\
\text { than switching } \\
\text { to S.U. } \\
\text { monotherapy. }\end{array}$ \\
\hline $\begin{array}{l}\text { Cavender et } \\
\text { al. } 2018 \\
8 \\
\text { (Sweden, } \\
\text { USA, UK, } \\
\text { Denmark, \& } \\
\text { Norway) }\end{array}$ & $\begin{array}{l}\text { Prospective cohort } \\
\text { study involved } \\
306,156 \text { T2DM } \\
\text { patients who were } \\
\text { newly started on } \\
\text { ADD. }\end{array}$ & $\begin{array}{l}\text { To investigate } \\
\text { the association } \\
\text { between the } \\
\text { initiation of } \\
\text { SGLT2i and CV } \\
\text { events compared } \\
\text { to other ADD. }\end{array}$ & • & $\begin{array}{l}\text { Compared with other ADD, } \\
\text { initiation of SGLT2i reduced } \\
\text { the risk of H.F. in patients with } \\
\text { (H.R.: } 0.72 ; 95 \% \mathrm{Cl}: 0.63-0.82) \\
\text { and without CVD (H.R.: } 0.61 ; \\
95 \% \mathrm{Cl}: 0.48-0.78) \text {, respectively. }\end{array}$ & $\begin{array}{l}\text { Initiating SGLT2i } \\
\text { treatment in } \\
\text { patients with or } \\
\text { without CVD } \\
\text { demonstrated a } \\
\text { lesser incidence } \\
\text { of H.F. } \\
\text { compared to } \\
\text { other ADD. }\end{array}$ \\
\hline
\end{tabular}


Con't

\begin{tabular}{|c|c|c|c|c|c|}
\hline $\begin{array}{l}\text { Lee et al. } 2019 \\
16 \\
\text { (South Korea) }\end{array}$ & $\begin{array}{l}\text { A nationwide cohort } \\
\text { study included } \\
98,383 \text { patients } \\
\text { newly prescribed } \\
\text { with SU, DPP4i, or } \\
\text { TZD as add-on } \\
\text { therapy to } \\
\text { metformin. }\end{array}$ & $\begin{array}{l}\text { To assess the } \\
\text { effect of adding } \\
\text { SU, DPP } 4 \mathrm{i} \text {, and } \\
\text { TZD to metformin } \\
\text { - on the risk of } \\
\text { H.F. } \\
\text { hospitalization. }\end{array}$ & $\bullet$ & $\begin{array}{l}\text { There was a significant } \\
\text { decrease in the risk of } \mathrm{H} . \mathrm{F} \text {. } \\
\text { hospitalization when using } \\
\text { metformin plus DPP4i (aHR: } \\
0.76,95 \% \mathrm{Cl} 0.69-0.84 \text { ) } \\
\text { compared to metformin plus } \\
\text { S.U. } \\
\text { There was no significant } \\
\text { difference shown with the use } \\
\text { of metformin plus TZD } \\
\text { (adjusted H.F.: } 0.96,95 \% \mathrm{Cl} \\
0.79-1.17 \text { ) compared to } \\
\text { metformin plus S.U. }\end{array}$ & $\begin{array}{l}\text { When used as } \\
\text { add-on } \\
\text { therapy to } \\
\text { metformin, } \\
\text { DPP4i reduced } \\
\text { the risk of } \\
\text { H.F. } \\
\text { hospitalization } \\
\text { compared } \\
\text { with S.U. and } \\
\text { TZD. }\end{array}$ \\
\hline $\begin{array}{l}\text { Roumie et al. } \\
2019^{29} \\
\text { (USA) }\end{array}$ & $\begin{array}{l}\text { Retrospective cohort } \\
\text { study included } \\
174882 \text { of diabetic } \\
\text { veterans with } \\
\text { reduced kidney } \\
\text { function. }\end{array}$ & $\begin{array}{l}\text { To compare the } \\
\text { CV safety of S.U. } \\
\text { vs. metformin. }\end{array}$ & $\bullet$ & $\begin{array}{l}\text { The findings revealed a total of } \\
1048 \text { MACE among metformin } \\
\text { users and a total of } 1394 \text { events } \\
\text { among S.U.s users. }\end{array}$ & $\begin{array}{l}\text { Metformin is } \\
\text { associated } \\
\text { with lower CV } \\
\text { risk compared } \\
\text { with S.U. } \\
\text { among } \\
\text { diabetic } \\
\text { patients with } \\
\text { reduced renal } \\
\text { function. }\end{array}$ \\
\hline
\end{tabular}

Abbreviations: ADD antidiabetic drug, H.F. heart failure, S.U. sulfonylurea, MI myocardial infarction, CV cardiovascular, TZD thiazolidinediones, aRR adjusted risk ratio, H.R. hazard ratio, aHR adjusted hazard ratio, $\mathrm{Cl}$ confidence interval, CVD cardiovascular disease, T2DM type 2 diabetes mellitus, IHD ischemic heart disease, DPP4i Dipeptidyl peptidase-4 inhibitor, SGLT2i Sodium-glucose Cotransporter 2 Inhibitors, CAD coronary artery disease, MACE major adverse cardiovascular events

In a retrospective Korean cohort study, the findings suggested that Asian diabetic patients could have higher benefits, such as achieving average baseline blood glucose in patients with lower body mass index, by using DPP4i relative to other ethnic groups. ${ }^{22}$ Furthermore, the data from Taiwan's National Health Insurance Research Database indicated that DPP4i had lower risks for cardiovascular complications as compared to those not receiving DPP4i, except for metformin. ${ }^{12}$ Besides, DPP4i was associated with a decreased risk of hospitalisation for CVDs among patients with a history of visits for CVDs compared to glimepiride. ${ }^{27}$

In addition, data from meta-analysis indicated a decreasing risk of MACE hospitalisation or death among saxagliptin users. ${ }^{35}$ Compared to other oral ADDs except TZD, DPP4i reported a decrease in allcause mortality and heart failure by $18 \%$ and $14 \%$, respectively. ${ }^{23}$ The data on DPP4i highlighted the effect of ethnicity on the net benefits of oral ADD. It also offered some important insights into the variation in $\mathrm{CV}$ outcomes by modifying one $\mathrm{ADD}$ in combination therapy.

Supported with growing evidence, SGLT2i showed a better CV safety profile compared to DDP4i in terms of the risk of H.F. hospitalization, especially in elderly patients with diabetic complications. ${ }^{26}$ The relative preference of SGLT2i over DPP4i for cardiac protective action was underpinned among patients with underlying CVD compared to those with no underlying CVD. ${ }^{13}$ Moreover, in a multinational study, initiation of SGLT2i has been associated with an overall lower incidence of H.F. in patients with or without underlying CVD compared to other ADDs. ${ }^{8}$ Similarly, another assessment involved data from six countries supported the CV outcomes of SGLT2i over other ADDs in terms of reducing H.F. hospitalization and death. ${ }^{36}$ Interestingly, consistent with the evidence supporting the favourable impact of SGLT2i on CV outcomes, empagliflozin, and canagliflozin demonstrated lower risks of H.F. Hospitalization compared to placebo. ${ }^{37}$ Fortunately, the benefits of SGLT2i in lowering the risk of admission with H.F. and death were consistent across the SGLT2i class but with a descending ranking order of relative preference as empagliflozin, dapagliflozin, and canagliflozin. ${ }^{36}$

Acarbose, which is indicated to normalize postprandial hyperglycemia, could reduce the oxidative stress and, therefore, prevent endothelial dysfunction that could lead to cardiovascular 
disease. $^{38}$ A nationwide study from Taiwan established that acarbose treatment either as monotherapy or in combination with the other ADDs in patients with T2DM without pre-existing CVD showed a temporary escalation in the incidence of cardiovascular complication in the first 12 months followed by the substantial declination of cardiovascular disease in the persistent use of acarbose population. ${ }^{10}$ According to the Acarbose Cardiovascular Evaluation trial, acarbose users did not get any direct CV protective effects compared to placebo, and the only difference reported was in the less frequency of developing diabetes among current users. ${ }^{39}$ Therefore, it is thought that the prolonged use of acarbose might indirectly reduce $\mathrm{CV}$ events by slowing or preventing hyperglycemia in people with CHD. Also, the add-on therapy by using acarbose with metformin is preferable compared to sulfonylureas due to their lower risk of cardiovascular adverse effects, although this effect was not significant in patients associated with a history of heart failure. ${ }^{14}$ On the contrary, another nationwide cohort study based on the Taiwan National Health Insurance Database a higher risk of hospitalization for ischemic stroke, heart failure, and myocardial infarction in diabetic patients who use initial therapy receiving acarbose compared to metformin initiators. ${ }^{11}$ Furthermore, acarbose did not reduce the risk of MACE in Chinese patients with CHD and impaired glucose tolerance but had an impact on reducing the incidence of diabetes compared to placebo. ${ }^{39}$

TZD, such as pioglitazone and rosiglitazone, are approved as highly selective peroxisome proliferator -activated receptor $\gamma$ agonists, which could manage inflammatory modulators and at once reduce the risk of coronary atherosclerosis. ${ }^{17}$ Pioglitazone was correlated with a $31 \%$ to $39 \%$ lesser risk of all-cause mortality in comparison to metformin. Additionally, pioglitazone had an advantage over rosiglitazone by increasing the high-density lipoprotein concentration and lowering the triglycerides concentrations, and therefore, it could reduce the progression rate on the thickness of carotid intima-media and indirectly decrease the risk of coronary atherosclerosis. ${ }^{17}$ Furthermore, lower risks for death and heart failure were established for pioglitazone. This result indicated that rosiglitazone has less favourable safety profile compared to pioglitazone. ${ }^{19}$ On the other hand, the data from the Korean Diabetes
Association showed that TZD as an add-on medication to metformin has no significant reduction of the risk of H.F. hospitalization in diabetic patients compared to metformin plus S.U. Hence, concerning this issue, TZD might not be a preferred $A D D$ for patients at high risk of H.F. hospitalization. ${ }^{16}$ Furthermore, in a retrospective cohort study conducted in the UK to compare the CV risk of ADD added to metformin therapy, TZD showed a significantly lower CVD risk and death compared to S.U. Whereas DPP4i showed a trend of a statistically insignificant lower risk. ${ }^{40}$ So, in patients with CVD and diabetes, a careful selection of the ADD should consider the underlying CVD disease and patient characteristics. In the absence of heart failure, both metformin and SGLT2i were consistent in demonstrating $\mathrm{CV}$ safety benefits. Further addition of TZD, DPP4i, then lastly S.U. agents could be considered for combination therapies. In the case of concomitant heart failure, there is evidence supporting the relative preference of SGLT2 $i$ agents to be included in the diabetes pharmacotherapy plan. ${ }^{41}$

\section{CONCLUSION}

Referring to the highlighted variations in the degree of CV protection between the various ADDs, few issues merit consideration by the prescriber, such as the effectiveness of the use of ADD between different genders and patient groups. Also, the comparison of CV safety of agents of the same class of drugs and the special precautions needed for individual agents should be considered. These issues may affect weighing the risks and benefits for each agent, and hence recommendations should be individualised. Considering that the use of $A D D$ combination therapies is increasingly seen in the practice as supported by the guidelines, so more supporting evidence concerning the $\mathrm{CV}$ outcomes of ADD combination therapy is still needed.

\section{ACKNOWLEDGMENT}

This work was supported by the Research Management Center of the International Islamic University Malaysia under grant number RIGS17-1220697. 


\section{DISCLOSURE}

The authors report no conflicts of interest in this work.

\section{REFERENCES}

1. American Diabetes Association. Classification and diagnosis of diabetes. Diabetes Care. 2017;40(January):S11-S24.

2. Panicker GK, Karnad DR, Salvi V, Kothari S. Cardiovascular risk of oral antidiabetic drugs: Current evidence and regulatory requirements for new drugs. $J$ Assoc Physicians India. 2012;60(1):56-61.

3. Dhindsa DS, Sandesara PB, Shapiro MD. The Intersection of Diabetes and Cardiovascular Disease-A Focus on New Therapies. Front Cardiovasc Med. 2018;5(November):1-9.

4. Rosenstock J, Marx N, Kahn SE, et al. Cardiovascular outcome trials in type 2 diabetes and the sulphonylurea controversy: Rationale for the active-comparator CAROLINA trial. Diabetes Vasc Dis Res. 2013;10(4):289-301.

5. Elnaem MH, Nik Mohamed MH, Huri HZ, Azarisman SM. Patterns of statin therapy prescribing among hospitalized patients with Type 2 diabetes mellitus in two Malaysian tertiary hospitals. Tropical Journal of Pharmaceutical Research. Vol 16. ; 2017:A178.

6. Elnaem MH, Nik Mohamed MH, Zaman Huri H, Azarisman SM. Effectiveness and prescription pattern of lipid-lowering therapy and its associated factors among patients with type 2 diabetes mellitus in Malaysian primary care settings. Ther Clin Risk Manag. 2019;18 (15):137-145

7. Cho EH, Park SJ, Han S, Song JH, Lee K, Chung YR. Potent oral hypoglycemic agents for microvascular complication: Sodiumglucose cotransporter 2 inhibitors for diabetic retinopathy. J Diabetes Res. 2018;2018.

8. Cavender MA, Norhammar A, Birkeland KI, et al. SGLT-2 Inhibitors and Cardiovascular Risk: An Analysis of CVD-REAL. J Am Coll Cardiol. 2018;71(22):2497-2506.

9. Schramm TK, Gislason GH, Vaag A, et al. Mortality and cardiovascular risk associated with different insulin secretagogues compared with metformin in type 2 diabetes, with or without a previous myocardial infarction: A nationwide study. Eur Heart J. 2011;32 (15):1900-1908.

10. Chen JM, Chang CW, Lin YC, Horng JT, Sheu WHH. Acarbose treatment and the risk of cardiovascular disease in type 2 diabetic patients: A nationwide seven-year follow-up study. J Diabetes Res. 2014;2014(812628).

11. Chang $\mathrm{CH}$, Chang YC, Lin JW, Chen ST, Chuang LM, Lai MS. Cardiovascular risk associated with acarbose versus metformin as the first-line treatment in patients with type 2 diabetes: $\mathrm{A}$ nationwide cohort study. J Clin Endocrinol Metab. 2015;100(3):1121-1129.

12. Ou HT, Chang KC, Li CY, Wu JS. Risks of cardiovascular diseases associated with dipeptidyl peptidase- 4 inhibitors and other antidiabetic drugs in patients with type 2 diabetes: A nation-wide longitudinal study. Cardiovasc Diabetol. 2016;15(1):1-13.

13. Kim YG, Han SJ, Kim DJ, Lee KW, Kim HJ. Association between sodium glucose cotransporter 2 inhibitors and a reduced risk of heart failure in patients with type 2 diabetes mellitus: A real-world nationwide populationbased cohort study. Cardiovasc Diabetol. 2018;17(1):1-9.

14. Chan CW, Yu CL, Lin JC, et al. Glitazones and alpha-glucosidase inhibitors as the second-line oral anti-diabetic agents added to metformin reduce cardiovascular risk in Type 2 diabetes patients: A nationwide cohort observational study. Cardiovasc Diabetol. 2018;17(1):1-13.

15. Douros A, Aniello SD, Hoi O, et al. Sulfonylureas as second line drugs in type 2 diabetes and the risk of cardiovascular and hypoglycaemic events: Population based cohort study. BMJ. 2018;362.

16. Lee SJ, Ha KH, Lee JH, Lee H, Kim DJ, Kim HC Second-line glucose-lowering drugs added to metformin and the risk of hospitalization for heart failure: A nationwide cohort study. PLoS One. 2019;14(2):1-10.

17. Tzoulaki I, Molokhia M, Curcin V, et al. Risk of cardiovascular disease and all cause mortality among patients with type 2 diabetes prescribed oral antidiabetes drugs: Retrospective cohort study using UK general practice research database. BMJ. 2009;339 (7736):35.

18. Zeller M, Danchin N, Simon D, et al. Impact of type of preadmission sulfonylureas on 
mortality and cardiovascular outcomes in diabetic patients with acute myocardial infarction. J Clin Endocrinol Metab. 2010;95 (11):4993-5002.

19. Gallagher AM, Smeeth L, Seabroke S, Leufkens HGM, van Staa TP. Risk of death and cardiovascular outcomes with thiazolidinediones: A study with the general practice research database and secondary care data. PLoS One. 2011;6(12).

20. Roumie CL, Hung AM, Greevy RA, et al. Comparative effectiveness of sulfonylurea and metformin monotherapy on cardiovascular events in type 2 diabetes mellitus: A cohort study. Ann Intern Med. 2012;157(9):601-610.

21. Mogensen UM, Andersson C, Fosbøl EL, et al. Sulfonylurea in combination with insulin is associated with increased mortality compared with a combination of insulin and metformin in a retrospective Danish nationwide study. Diabetologia. 2015;58(1):50-58.

22. Shin S, Kim H, Press D. The effect of sitagliptin on cardiovascular risk profile in Korean patients with type 2 diabetes mellitus: A retrospective cohort study. Ther Clin Risk Manag. 2016;12:435-444.

23. Hippisley-Cox J, Coupland C. Diabetes treatments and risk of heart failure, cardiovascular disease, and all cause mortality: Cohort study in primary care. BMJ. 2016;354.

24. Heaton PC, Desai VCA, Kelton CML, Rajpathak SN. Sulfonylurea use and the risk of hospital readmission in patients with type 2 diabetes. BMC Endocr Disord. 2016;16(1):1-10.

25. Hsu CY, Su YW, Chen YT, Tsai SH, Chang CC, Li SY. Association between use of oral $\square$ antidiabetic drugs and the risk of aortic aneurysma: a nested case - control analysis. Cardiovasc Diabetol. 2016;15(125):1-8.

26. Gautam S, Agiro A, Barron J, Power T, Weisman $\mathrm{H}$, White J. Heart failure hospitalization risk associated with use of two classes of oral antidiabetic medications: An observational, real-world analysis. Cardiovasc Diabetol. 2017;16(1):1-10.

27. Chin HJ, Nam JH, Lee EK, Shin JY, Chang J. Comparative safety for cardiovascular outcomes of DPP-4 inhibitors versus glimepiride in patients with type 2 diabetes: A retrospective cohort study. Med (United States). 2017;96(25):1-8.

28. Raghavan S, Liu WG, Saxon DR, et al. Oral diabetes medication monotherapy and shortterm mortality in individuals with type 2 diabetes and coronary artery disease. $B M \mathrm{~J}$ Open Diabetes Res Care. 2018;6(1):1-11.

29. Roumie CL, Chipman J, Min JY, et al. Association of Treatment With Metformin vs Sulfonylurea With Major Adverse Cardiovascular Events Among Patients With Diabetes and Reduced Kidney Function. JAMA. 2019:1-11.

30. Elnaem MH, Cheema E. Caring for patients with diabetes during COVID-19 pandemic: Important considerations for pharmacists. Res Social Adm Pharm. 2020;(May):0-1.

31. Eurich DT, Weir DL, Majumdar SR, et al. Comparative safety and effectiveness of metformin in patients with diabetes mellitus and heart failure systematic review of observational studies involving 34000 patients. Circ Hear Fail. 2013;6(3):395-402.

32. Hong J, Zhang $\mathrm{Y}$, Lai $\mathrm{S}$, et al. Effects of metformin versus glipizide on cardiovascular outcomes in patients with type 2 diabetes and coronary artery disease. Diabetes Care. 2013;36(5):1304-1311.

33. Wang SH, Chen WJ, Hsu LY, Chien KL, Wu CS. Use of spontaneous reporting systems to detect host-medication interactions: Sex differences in oral anti-diabetic drugassociated myocardial infarction. J Am Heart Assoc. 2018;7(22):1-10.

34. Douros A, Dell'Aniello S, Yu OHY, Filion KB, Azoulay L, Suissa S. Sulfonylureas as second line drugs in type 2 diabetes and the risk of cardiovascular and hypoglycaemic events: Population based cohort study. BMJ. 2018;362.

35. Lo Re V, Carbonari DM, Elle Saine M, et al. Postauthorization safety study of the DPP-4 inhibitor saxagliptin: A largescale multinational family of cohort studies of five outcomes. BMJ Open Diabetes Res Care. 2017;5(1):1-16.

36. Kosiborod M, Cavender MA, Fu AZ, et al. Lower risk of heart failure and death in patients initiated on sodium-glucose cotransporter- 2 inhibitors versus other glucose-lowering drugs: The CVD-REAL study (Comparative Effectiveness of Cardiovascular Outcomes in New Users of Sodium-Glucose Cotranspo. Circulation. 2017;136(3):249-259.

37. Neal B, Perkovic V, Mahaffey KW, et al. Canagliflozin and cardiovascular and renal 
events in type 2 diabetes. $N$ Engl $J$ Med.

2017;377(7):644-657.

38. Standl E, Theodorakis MJ, Erbach M, Schnell O, Tuomilehto J. On the potential of acarbose to reduce cardiovascular disease. Cardiovasc Diabetol. 2014;13(1).

39. Holman RR, Coleman RL, Chan JCN, et al. Effects of acarbose on cardiovascular and diabetes outcomes in patients with coronary heart disease and impaired glucose tolerance (ACE): a randomised, double-blind, placebocontrolled trial. Lancet Diabetes Endocrinol. 2017;5(11):877-886.

40. Zghebi SS, Steinke DT, Rutter MK, Emsley RA, Ashcroft DM. Comparative risk of major cardiovascular events associated with secondline antidiabetic treatments: a retrospective cohort study using UK primary care data linked to hospitalisation and mortality records.

Diabetes Obes Metab. 2016;18(9):916-924.

41. Rådholm K, Wu JHY, Wong MG, et al. Effects of sodium-glucose cotransporter-2 inhibitors on cardiovascular disease, death and safety outcomes in type 2 diabetes - A systematic review. Diabetes Res Clin Pract. 2018;140:118128. 